Voix et Images

voixetimages

\title{
Géométries variables
}

\section{Martine-Emmanuelle Lapointe}

Volume 38, numéro 2 (113), hiver 2013

Louis Dantin

URI : https://id.erudit.org/iderudit/1015170ar

DOI : https://doi.org/10.7202/1015170ar

Aller au sommaire du numéro

\section{Éditeur(s)}

Université du Québec à Montréal

\section{ISSN}

0318-9201 (imprimé)

1705-933X (numérique)

Découvrir la revue

Citer ce compte rendu

Lapointe, M.-E. (2013). Compte rendu de [Géométries variables]. Voix et Images, 38(2), 132-137. https://doi.org/10.7202/1015170ar d'utilisation que vous pouvez consulter en ligne.

https://apropos.erudit.org/fr/usagers/politique-dutilisation/ 


\section{R O M A N}

Géométries variables

$++$

MARTINE-EMMANUELLE LAPOINTE

Université de Montréal

La parution de La fiancée américaine ${ }^{1}$ d'Éric Dupont à l'automne 2012 n'est pas passée inaperçue. Les critiques de nombreux quotidiens québécois ont le plus souvent salué l'admirable talent de conteur de l'auteur et le caractère riche, complexe et foisonnant des multiples histoires qu'il a su réunir dans son ample roman. La fiancée américaine est sans contredit une œuvre ambitieuse qui se présente à la fois sous la forme d'une saga familiale, d'une fresque historique, d'un récit de filiation, et qui ose également conjuguer des genres et des tons différents. Le conte folklorique, l'absurde, le réalisme magique, le journal intime, l'échange épistolaire s'entrelacent et donnent lieu à un texte composite, sorte de collection de petits romans reliés les uns aux autres par l'histoire de quatre générations issues d'une même lignée. Cette remarquable liberté d'écriture, qui est au fondement même de l'art romanesque, notons-le, n'est pas sans rappeler le style de certains romans fleuves parus au Québec dans les années 1980-1990. Les Chroniques du Plateau-Mont-Royal ${ }^{2}$ de Michel Tremblay ou encore Maryse et Myriam première ${ }^{3}$ de Francine Noël, best-sellers reçus favorablement par la critique, entretiennent eux aussi un rapport « décomplexé » à l'écriture et à l'Histoire, s'approprient librement les codes de la fiction, se jouent des catégories et des étiquettes. Sans en être absents, le travail sur l'écriture et l'exploration formelle s'y accompagnent d'un constant souci de lisibilité, d'un goût marqué pour le récit, l'anecdote, l'humour. C'est dans cette filiation-là, me semble-t-il, que s'inscrit La fiancée américaine.

À Rivière-du-Loup, en 1917, Madeleine-la-Mére, matriarche et mémoire vivante de la famille Lamontagne, tente de trouver une fiancée prénommée Madeleine à son fils Louis-Benjamin. Après des recherches infructueuses et des fiançailles rompues ${ }^{4}$, elle devra se tourner vers son frère exilé aux États-Unis qui aurait adopté « une petite Madeleine, orpheline de Canadiens français» (17). Quelques mois plus tard

$$
+++
$$

1 Éric Dupont, La fiancée américaine, Montréal, Marchand de feuilles, 2012, 560 p. 2 Michel Tremblay, Chroniques du Plateau-Mont-Royal, Montréal/Arles, Leméac/Actes Sud, coll. "Thésaurus», 2012, 1171 pages. 3 Francine Noël, Maryse, Montréal, Bibliothèque québécoise, 1994 [1983], 523 p. et Myriam première, Montréal, VLB éditeur, 1987, 532 pages. 4 La première Madeleine promise à Louis-Benjamin « avait été emportée en une semaine par la grippe espagnole qui décimait les villages de la côte» (17). 
débarque à Rivière-du-Loup la fameuse fiancée américaine du titre, rousse aux yeux sarcelle, unilingue anglophone, cuisinière accomplie, qui séduit en un regard le beau Louis-Benjamin : «C'est donc un coup de foudre, ou son équivalent nordique, l'aurore boréale, qui marqua la première rencontre entre le costaud Lamontagne et Madeleine l'Américaine. » (19) Leur idylle ne durera pas un an: Madeleine l'Américaine meurt en couches après avoir donné naissance à Louis, surnommé plus tard le Cheval Lamontagne en raison de sa force et de sa taille surhumaines. C'est autour de ce héros singulier que s'organisera plus du tiers du roman. Homme fort se donnant en spectacle sur les routes des États-Unis, enrôlé dans l'armée américaine pendant la Deuxième Guerre mondiale, le bellâtre fort en gueule multiplie les aventures et les conquêtes avant de fonder une famille et de devenir le croque-mort vedette de Rivière-du-Loup. La suite du roman s'attache aux descendants de Louis Lamontagne, soit sa fille Madeleine et ses petits-fils Gabriel et Michel. À leurs voix s'ajoute celle de Magdalena Berg, la voisine berlinoise de Gabriel. Ce double lointain de Madeleine Lamontagne relate dans ses trois cahiers sa jeunesse vécue pendant la Deuxième Guerre mondiale. Sans être dépourvues d'intérêt, les dernières parties du roman ne revêtent pas la même truculence stylistique et narrative que les chapitres consacrés aux exploits et aux récits hyperboliques du Cheval Lamontagne.

L'adjectif «hyperbolique» convient d'ailleurs parfaitement au personnage du Cheval Lamontagne, qui est plus grand que nature, un peu à la manière des héros traditionnels, dont les vices comme les vertus ont un caractère excessif. Une scène du roman témoigne de manière particulièrement éloquente de l'aura de légende qui accompagne ce personnage à la réputation sulfureuse. À son retour d'Europe, il est le héros du défilé de la Saint-Jean-Baptiste:

\footnotetext{
Et la clameur partit. Peut-être plus fort encore que pendant le défilé de la victoire des troupes canadiennes à leur retour d'Europe. Louis avait, lui, combattu au sein des troupes du vrai vainqueur. Qu'on le sache! Peut-être Hollywood avait-elle trop bien traité l'armée américaine... Quoi qu'il en soit, Louis Lamontagne apparaissait sous les yeux des Louperivois comme celui qui, de ses mains nues, avait étranglé le serpent du fascisme. Que Staline aille se rasseoir! Contrairement à ses concitoyens, Louis avait servi une vraie armée, une armée qu'on voit au cinéma! Louis marchait, souriant, sous les yeux de toute la ville. (107)
}

Et c'est bien sous le regard de toute la ville qu'évoluera, de sa naissance à sa mort, le personnage du Cheval Lamontagne. Objet du désir d'autrui, il devient l'écran sur lequel sont projetés les fantasmes et les obsessions de la collectivité, et ne semble se définir qu'en fonction de ceux-ci.

Le récit des années plus lointaines, campées dans la petite ville de Rivièredu-Loup, convainc aisément. Multipliant les situations et les anecdotes improbables, il repose sur des trouvailles stylistiques, des comparaisons inédites, des réécritures - notamment celle des «comices agricoles» de Flaubert qui sont ici transposées dans une foire états-unienne. Il récupère également certaines figures du folklore québécois, mais ne tend nullement vers l'éloge de l'austérité et du conservatisme. La religion, par exemple, n'y est pas conçue uniquement comme une forme de censure morale ou 
de repoussoir des péchés et des vices humains. Elle est présentée de manière triviale et grotesque à la fois, quasi carnavalesque : le curé y est gourmand et sensuel, goûtant « tout particulièrement le bonheur de se retrouver dans une salle à manger de l'habitant grouillant d'enfants morveux » (31); les religieuses osent y annoncer une fausse fin du monde pour enseigner à leurs pupilles «la mécanique de l'humiliation et du châtiment» (128); un jeune prêtre s'éprend fiévreusement d'un frère et d'une sœur alors qu'il peint un nouveau chemin de croix pour l'église de la paroisse Saint-FrançoisXavier. Le couvent des sœurs de l'Enfant-Jésus, protectrices et mères tutélaires du Cheval Lamontagne, est habité jusqu'en l'an 2000 par le fantôme de Madeleinela-Mére pourtant morte le jour de l'accession au pouvoir d'Adolf Hitler. Lieu spectral, le couvent survit d'ailleurs à toutes les époques et porte le souvenir du passé et la connaissance de l'avenir, permettant aux descendants de Louis Lamontagne de redécouvrir le secret de leurs origines perdues (404). On l'aura compris, la religion n'est pas traitée de manière réaliste, bien au contraire: fait social, répertoire de fables et de légendes, survivance d'un passé sans enluminures, elle n'est absolument pas vraisemblable. Et pourtant elle emporte l'adhésion, comme si l'imaginaire plus ancien qu'elle convoquait pouvait se draper d'irréalité.

La suite du roman, consacrée à l'édification du Groupe Mado inc. par Madeleine et son amie Solange, aux parcours croisés de Gabriel et de Michel ainsi qu'à l'histoire de Magdalena Berg, couvre les années 1960 à 2000, et a pour principaux cadres Montréal et Berlin. Si les échanges épistolaires de Gabriel et de Michel constituent la partie la plus convenue du roman, les cahiers de Magdalena Berg permettent en revanche de revenir sur certains épisodes méconnus de la Deuxième Guerre mondiale, et de témoigner de manière différée des atrocités commises par les nazis envers les Juifs, les homosexuels et les handicapés allemands. L'image d'un zèbre terrifié, fulgurante et terrible à la fois, semble à elle seule condenser les émotions alors vécues par Magdalena Berg:

\footnotetext{
Une bombe avait dû abattre un des murs de l'enclos. Je n'oublierai jamais l'image de cette bête affolée, galopant dans les ruines incandescentes. Le feu était pris à mon manteau. Je dus l'enlever pour ne pas devenir torche humaine. Le zèbre galopait dans ma direction, j'étais pétrifiée par la terreur, incapable de bouger. Son souffle me parcourut le cou, il me parut froid par rapport à l'air ambiant, puis la bête hennit, me frôla dans sa course vers la ville. Je la perdis de vue dans un nuage de fumée. (429)
}

Il importe enfin de souligner que le roman d'Éric Dupont est truffé de coïncidences, lesquelles sont redoublées par les nombreuses références culturelles émaillant le récit. Madeleine et Magda partagent des histoires similaires; Königsberg se mire dans Montréal, et vice-versa ; l'opéra Tosca, la Mise au tombeau de la Vierge, "Que ma joie demeure » de Bach constituent des motifs récurrents dans toutes les intrigues. Vers la fin du roman, les hasards et les effets d'écho se multiplient au point de conférer un caractère absolument artificiel au dénouement. Tout se règle comme par magie. La fiancée américaine flirte bien avec le réalisme magique, se permet des tours et des trucs, mais aussi des facilités, comme dans les opéras que l'auteur cite abondamment. Le personnage de Madeleine aura d'ailleurs ces mots, qui auraient pu servir d'exergue 
à la présente chronique : «Moi, je trouve ça beau l'opéra, mais les histoires ne tiennent pas debout.» (491) Dans La fiancée américaine, les histoires ne tiennent pas toujours debout, mais elles sont bel et bien portées par un plaisir d'écriture, par un souffle rarement rencontré dans le roman québécois contemporain. Cela mérite d'être salué.

Hollywood ${ }^{5}$ de Marc Séguin partage peu de traits avec La fiancée américaine. Roman bref, tout en intériorité, nourri de tragédies inspirées par l'histoire récente, il s'en prend à la violence et aux inégalités à peine voilées de l'imaginaire hollywoodien, d'où son titre qui est une sorte de pied de nez à l'American dream. Si le roman dénonce d'emblée les procédés du cinéma populaire américain, il se permet néanmoins de jouer sciemment avec certains des codes les plus usés de celui-ci : surenchère, coïncidences étonnantes, tragédies en écho, errance semée d'embûches d'un héros solitaire en constituent la trame. Le 24 décembre 2009, à Jersey City, le narrateur du roman voit Branka, sa conjointe enceinte - elle-même rescapée de la guerre en ex-Yougoslavie mourir en pleine rue après avoir été touchée par une balle perdue. Il sauve le bébé, puis s'enfuit. Déjà lourde de symboles, cette scène traumatique annonce la suite d'un récit fondé sur l'accumulation, voire la surimpression, de mauvais hasards. À l'histoire de Branka se greffe celle de Stan. Né d'un père ukrainien et d'une mère tchétchène, il grandit au Québec, s'engage volontairement dans le conflit en ex-Yougoslavie, puis devient médecin et astronaute pour la Russie. Il est l'agresseur et l'amoureux de Branka, mais également l'ami d'enfance du narrateur. Il meurt lui aussi le 24 décembre 2009, «étouffé par le vide sidéral» (56).

Le narrateur, quant à lui, se présente comme un simple témoin des histoires (trop) remplies de ses proches; pire, il est une sorte de mort en sursis. Dès le début du roman, il déclare:

Je n'ai pas vécu de guerre [...]. Je n'ai pas vécu l'exil, je ne suis pas apatride, déporté, orphelin, miséreux ni sinistré. Je n'ai pas la peau noire au milieu d'une majorité blanche. [...] Je ne sais de la nature humaine que ce que les livres, la télévision ou le quotidien américain veulent bien célébrer et financer. Quand on connaît un mort, il me semble qu'on est plus vivant que les autres. (8)

Et c'est bien le spectacle de son propre ennui, de son vide, que les destins croisés de Branka et de Stan semblent rompre. À la fin du roman, le lecteur n'aura rien appris ou presque de la vie du narrateur. Même lors de son errance post-traumatique, ce dernier échoue chez un couple qui a vécu des choses. Après avoir été déçus par le rêve américain, Henri et Sarah ont choisi de se réfugier dans la marge en squattant un garage désaffecté, «[v]ivant essentiellement des surplus de leur société» (98).

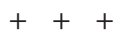

5 Marc Séguin, Hollywood, Montréal, Leméac, 2012, 160 p. 
De cette matière romanesque touffue, Marc Séguin a malheureusement tiré un roman hautement moral, pour ne pas dire sentencieux. Les répliques du personnage de Branka, notamment, constituent presque toujours des leçons sur la vie, l'histoire, la culture. L'on a parfois l'impression d'être plongé dans la lecture d'un répertoire de maximes et d'aphorismes à rabais : «Tous les hommes naissent égaux. Peut-être. Mais tous les hommes vivent et meurent avec tellement d'inégalités.» (38) «L'illusion du bonheur est un piège dont très peu savent se déprendre. » (82) Ou encore «La foi nous déresponsabilise.» (109) Symbole plus que personnage incarné, Branka parle une langue artificielle qui peine à convaincre. Tout autant que les dialogues, la narration se tisse de réflexions existentielles qui confèrent à l'ensemble un caractère décousu. Tout se passe comme si le message l'emportait sur le récit et en minait le cours, renvoyant le lecteur au pessimisme diffus d'un narrateur en mal de repères.

Jean-Philippe Martel a publié son premier roman Comme des sentinelles ${ }^{6}$ à la très prometteuse maison d'édition La Mèche. Le canevas de son roman peut paraître banal: Vincent Sylvestre, jeune chargé de cours en littérature française à l'Université de Sherbrooke, commence à fréquenter les Narcotiques Anonymes à la suite de sa rupture amoureuse avec Evelyn. Il s'y lie d'amitié avec Robert Thompson, un bum au grand cœur. À ce récit premier s'entrelacent les souvenirs d'enfance du narrateur, consignés à la troisième personne dans de courts chapitres en italique qui s'attachent plus particulièrement à la figure du père et à la reconquête d'une mémoire intime et familiale. Ici encore, comme en de nombreux romans contemporains, affleurent les thèmes de la transmission, de la filiation et de la reconstruction de soi au sein du chaos ambiant. Jean-Philippe Martel a su traiter habilement ces questions en mettant en scène un narrateur clairvoyant, parfois acide, qui semble n'avoir foi en rien, surtout pas en lui-même. S'il a foi en quelque chose, ce serait peut-être en la littérature. Cette dernière n'est pas pour autant une planche de salut, loin s'en faut, mais bien une manière de lire le monde, d'y habiter à contretemps, comme en témoigne la réécriture du poème «Cortège» de Guillaume Apollinaire:

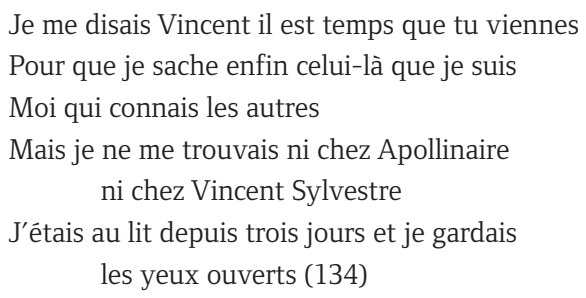

Refuge aux frontières poreuses, lieu d'un éphémère ressourcement, la littérature est aussi ce qui lie le personnage de Vincent au monde extérieur. Dans sa salle de

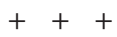

6 Jean-Philippe Martel, Comme des sentinelles, Montréal, La Mèche, 2012, 184 p. 
cours, il arrive à jouer un rôle, à se mettre en scène en s'inspirant des parcours et des fictions d'autrui. Plusieurs chapitres du roman présentent en effet des exposés didactiques, parfois inutilement lourds et détaillés, empruntés à ses cours sur l'histoire littéraire française. Ces passages servent souvent de prétextes à des retours introspectifs sur la pratique de l'enseignement universitaire, sur les rapports de force qui ne manquent pas de s'établir entre le professeur et ses étudiants, mais aussi sur l'éternel divorce entre la vie et le livre:

\begin{abstract}
Oui, je me suis bien vu leur dire que je n'en pouvais plus de me tenir là, gesticulant au milieu de rien, et que j'aurais donné n'importe quoi pour sentir que ma vie pouvait encore basculer dans l'ivresse ou dans l'extase, capoter dans les cataclysmes et la mort. Mais je suis resté tranquille, en parlant à ma douleur avec toutes sortes d'exclamations en «Ô». (102)
\end{abstract}

Il s'agit là sans doute du véritable objet de Comme des sentinelles: l'impression toute romantique de vivre en inadéquation avec ses propres désirs et idéaux, de passer à côté de la «vraie vie». Contrairement à Marc Séguin cependant, Jean-Philippe Martel contourne le piège du moralisme en ne jetant le blâme sur personne. La société de consommation, la famille, l'école ne sont pas responsables de la déroute de Vincent Sylvestre; elles font plutôt partie de l'horizon de celui-ci, l'ayant formé et déformé à la fois. Le dénouement du roman n'offre aucune réponse au désarroi du personnage, mais propose une plongée quasi sereine dans l'écriture. Loin d'être inédite, cette fin respecte l'univers romanesque de Martel. Sobre, écrit dans une langue maîtrisée, Comme des sentinelles ne cherche pas à multiplier les effets et parvient, en toute modestie, à contourner, tout en en jouant, les poncifs et les lieux communs de l'écriture contemporaine. 